\title{
STUDI LITERATUR TENTANG KEMAMPUAN PEMECAHAN MASALAH MATEMATIS MELALUI MODEL LEARNING CYCLE 7E DISEKOLAH MENENGAH
}

\author{
Reza Luisy Octaviana ${ }^{1}$, Taufik Rahman ${ }^{2}$ \\ ${ }^{1}$ Universitas Pasundan, ${ }^{2}$ Universitas Pasundan \\ rezaluisy10@gmail.com, taufikpmat@unpas.ac.id
}

\begin{abstract}
ABSTRAK
Penelitian ini merupakan penelitian kualitatif dengan metode studi kepustakaan yang memberikan informasi tentang pembelajaran matematika pada sekolah menengah dengan model learning cycle $7 e$ tentang kemampuan pemecahan masalah matematis. Tujuan penelitian ini adalah untuk menganalisis kemampuan pemecahan masalah matematismelalui model learning cycle $7 e$; Teknik analisis data menggunakan teknik deduktif, induktif, dan interpretasi. Hasil penelitian menunjukkan bahwa model pembelajaran learning cycle $7 E$ dapat meningkatkan kemampuan pemecahan masalah matematis siswa dan di sekolah menengah. Kemampuan yang paling rendah pada Indikator memeriksa kembali jawaban karena siswa merasa jawabannya sudah benar.
\end{abstract}

Kata kunci: learning cycle $7 e$, pemecahan masalah matematis, studi literartur

\begin{abstract}
This research is a qualitative research with a literature study method that providesinformation about mathematics learning in secondary schools with the 7e learning cycle model on mathematical problem solving abilities. The purpose of this study was to analyze mathematical problem solving skills through the 7e learning cycle model; Data analysis techniques used deductive techniques, inductive techniques, and interpretation techniques. The results showed that the Learning Cycle 7E learning model could improve students' mathematical problem solving abilities andin high school the lowest indicator was re-checking the answers because students felt the answers were correct.
\end{abstract}

Keywords: learning cycle 7e, mathematical problem solving.

\section{PENDAHULUAN}

Pendidikan adalah keseluruhan antarhubungan manusia untuk perkembangan manusia keseluruhan, dan pendidikan merupakan runtutan perubahan yang berkelanjutan yang terus menerus berkembang (Sutrisno, 2011, hlm.65). Salah satuformasi kehidupan yang paling penting adalah pendidikan matematika. Matematika berperan penting pada kehidupan karena dapat memperkuat daya pikir manusia. Matematika dibentuk oleh pemikiran manusia yang terkait dengan ide, proses, dan penalaran. (Russeffendi, 1980, hlm.148). 
Matematika di Indonesia belum memperlihatkan hasil yang memuaskan dapat dilihat dari survei yang dilakukan Trends in International Mathematics and Science Study (TIMSS) tahun 2015, Indonesia berada pada peringkat ke-44 dari 49peserta, dengan skor 397 dibawah skor rata-rata TIMSS yaitu 500 (NCES, 2018, hlm. 265). Sedangkan matematika sangat berpengaruh bagi kehidupan. Maka perludiperhatikan kemampuankemampuan dalam pembelajaran matematika.

Salah satu kemampuan yang harus dimiliki siswa adalah kemampuan siswa dalam memecahkan masalah matematis. Pemecahan masalah merupakan komponen penting, hal ini dinyatakan oleh Ruseffendi (2006) yang mengemukakan bahwa kemampuan pemecahan masalah penting dalam matematika, bukan saja bagi mereka yang di kemudian hari akan mendalami atau mempelajari matematika, melainkan juga bagi mereka yang akan menerapkannya dalam bidang studi lain dan dalam kehidupan sehari-hari. Untuk mencapai penguasaan matematika perlu dibangun sistem pembelajaran yang aktif, kreatif dan inovatif agar pembelajaran menjadi lebih optimal dan membawa hasil yang diharapkan. Oleh karena itu, diperlukan model pembelajaran yang tepat untuk meningkatkan kemampuan pemecahan masalah matematis. Salah satunya yaitu model learning cycle 7E. Model learning cycle 7E merupakan model yang melalui serangkaian langkah kegiatan yang diatur sedemikian rupa sehingga peserta didik dapat memperoleh kompetensi yang dibutuhkan sekaligus dapat berperan aktif dalam pembelajaran. Sintaks model learning cycle 7E meliputi indikator kemampuan pemecahan masalah matematika. Tahapan-tahapan learning cycle 7e meliputi Elicit, Engage, Explore, Explain, Elaborate, Evaluate, Extend.

Berdasarkan paparan diatas, maka penelitian ini berjudul Studi Literatur Tentang Kemampuan Pemecahan Masalah Matematis Melalui Model Learning Cycle 7e diSekolah Menengah yang memiliki tujuan untuk menganalisis dan mendeskripsikan kemampuan pemecahan masalah matematis siswa melalui model Learning cycle 7e.

\section{METODE PENELITIAN}

Penelitian ini merupakan penelitian kualitatif yang termasuk ke dalam jenis penelitian kepustakaan (Library research) yaitu mencatat semua temuan secara umum pada setiap artikel yang membahas tentang aspek pemecahan masalah matematis dan model Learning Cycle 7E. Teknik pengumpulan data yang digunakan yaitu: 1) editing yaitu penelitian data kembali, khususnya yang berkaitan dengan kelengkapan, kecerahan akal dan harmoni yang berarti antara satu sama lain; 2) organizing yaitu mengatur data yang 
diperoleh dengan kerangka yang direncanakan; 3) finding yaitu untuk menemukananalisis lebih lanjut terhadap hasil data melalui data, dan ditemukan kesimpulan yang merupakan hasil jawaban dari rumusan masalah. Adapun analisis data yang digunakan yaitu teknik deduktif, induktif, dan interpretasi. Sumber data yang digunakan dalam penelitian ini dibagi menjadi sumber primer dan sekunder. Sumber primer terdiri dari artikel-artikel dari berbagai jurnal yang telah dikumpulkan dan data sekunder berupa artikel serta buku.

\section{HASIL DAN PEMBAHASAN}

\section{Kemampuan Pemecahan Masalah Matematis Siswa}

Penelitian yang dilakukan oleh Putra, dkk (2018) dimana masih tergolong rendah. Banyaknya siswa yang mengikuti tes ini adalah 35 orang. Berikut adalah rata-rata indikator kemampuan pemecahan masalah matematis.

Tabel 1. Persentase indikator kemampuan pemecahan masalah matematis

\begin{tabular}{lccc}
\hline \multicolumn{1}{c}{ Indikator } & $\begin{array}{c}\text { Persentase } \\
\text { benar }\end{array}$ & $\begin{array}{c}\text { Persentase } \\
\text { Salah }\end{array}$ & Kriteria Kesalahan \\
\hline Memahami Masalah & 40,00 & 60,00 & Sangat Tinggi \\
Merencanakan penyelesaian & 57,14 & 42,86 & Tinggi \\
Menyelesaikan masalah & 54,28 & 45,72 & Tinggi \\
Menafsirkan solusi & 54,28 & 45,72 & Tinggi \\
\hline
\end{tabular}

Pada tabel 1 dapat dilihat bahwa kriteria kesalahan siswa tinggi dapat dikatakan bahwa kemampuan pemecahan masalah matematis siswa rendah.

Penelitian lainnya dilakukan oleh Kurniawan, dkk (2020) yaitu kemampuan pemecahan masalah matematis siswa mengalami peningkatan dengan menggunakan pendekatan PMRI melalui sistem LSLC. Indikator kemampuan pemecahan masalah matematis sudah dicapai siswa. Indikator yang belum dicapai adalah memeriksa atau melihat kembali kebenaran soal.

Adapun penelitian yang dilakukan oleh Rinaldi dan Afriansyah (2019) yang membandingkan model Problem Centered Learning dan Problem Based Learning pada kemampuan pemecahan masalah matematis di SMP kelas VIII sebanyak 31 siswa. Berikut adalah data yang diperoleh dari hasil pretest dan post-test.

Tabel 2. Data siswa menggunakan model Problem Centered Learning

\begin{tabular}{cccc}
\hline Kelas & \multicolumn{3}{c}{ Problem Centered Learning } \\
\hline Tes & Pretest & Post-test & Gain Ternormalisasi \\
Jumlah Siswa & 31 & 31 & 31 \\
Rata-Rata & 9,52 & 29,95 & 0,51 \\
\hline
\end{tabular}


Tabel 3. Data siswa menggunakan model Problem Based Learning

\begin{tabular}{cccc}
\hline Kelas & \multicolumn{3}{c}{ Problem Based Learning } \\
\hline Tes & Pretest & Post-test & Gain Ternormalisasi \\
Jumlah Siswa & 31 & 31 & 31 \\
Rata-Rata & 11,16 & 26,10 & 0,39 \\
\hline
\end{tabular}

Dari Tabel 2, dapat dilihat adanya kenaikan rata-rata pada saat post-test dimana sudah diberi perlakuan model pembelajaran.

\section{Kemampuan Pemecahan Masalah Matematis Melalui Model Learning Cycle 7e}

Penelitian yang dilakukan oleh Lestari dan Rosdiana (2018) di salah satu SMP kemampuan pemecahan masalah matematis siswa dengan menggunakan model learning cycle 7e. Berikut adalah tabel hasil tes siswa.

Tabel 4 Hasil pretest dan post-test siswa dengan model learning cycle 7e

\begin{tabular}{lcc}
\hline Keterangan & Pretest & Post-test \\
\hline Jumlah Siswa & 38 & 38 \\
Skor Ideal & 20 & 20 \\
Rata-rata x & 2,90 & 10,87 \\
Rata-rata \% & $14,48 \%$ & $54,35 \%$ \\
Simpangan Baku & 2,28 & 4,43 \\
\hline
\end{tabular}

Tabel 4 menunjukan terdapat peningkatan rata-rata dari hasil pretest ke post-test. Artinya kemampuan pemecahan masalah matematis siswa meningkat setelah diberimodel learning cycle 7e.

Penelitian yang dilakukan oleh Anshori, dkk. (2020) yaitu pengaruh learning cycle 7e jika didampingi mind mapping terhadap kemampuan pemecahan masalah matematis ditinjau dari Advertisy Quotient. Terdapat hasil data pretest yaitu saat siswa dalam pembelajarannya menggunakan model konvensional dan hasil post- test yaitu ketika siswa sudah diberi model learning cycle 7E.

Tabel 5 Hasil Pretest Siswa

\begin{tabular}{lccc}
\hline \multicolumn{1}{c}{ Kelas } & Rata-rata & Jumlah siswa & Persentase \\
\hline Kontrol & 54,09 & 32 & $31,1 \%$ \\
Eksperimen 1 & 54,40 & 34 & $33,3 \%$ \\
Eksperimen 2 & 54,94 & 36 & $35,6 \%$ \\
Total & 54,50 & 102 & $100 \%$ \\
\hline
\end{tabular}

Pada hasil pretest siswa kelas eksperimen 2 lebih baik daripada kelas eksperimen 1 dan kelas kontrol.

Tabel 6 Hasil Post-test siswa

\begin{tabular}{lccc}
\hline \multicolumn{1}{c}{ Kelas } & Rata-rata & Jumlah Siswa & Persentase \\
\hline Kontrol & 72,03 & 32 & $28,3 \%$ \\
Eksperimen 1 & 79,83 & 34 & $33,3 \%$ \\
Eksperimen 2 & 87,05 & 36 & $38,4 \%$
\end{tabular}


Hasil post-test yaitu hasil yang didapat dalam pengujian soal ketika pembelajaran siswa sudah diberi model learning cycle 7e. Kelas eksperimen 2 lebih unggul daripada kelas eksperimen 1 dan kelas kontrol. Dari kedua tabel tersebut dapat dilihat bahwa setelah diberi perlakuan model learning cycle 7E, rata-rata kemampuan siswa meningkat. Hasil analisis menunjukkan bahwa model learning cycle 7E disertai mind mapping membuat siswa lebih kritis pada materi pelajaran dan saat proses pembelajaran siswa terlibat langsung. Tentunya tidak dapat dipisahkan dari arahan atau bimbingan guru. Model learning cycle 7E disertai mind mapping juga memiliki pengaruh terhadap kemampuan pemecahan masalah dari semua kategori adversity quotient sehingga dapat mengatasi kesulitan belajar dalam perkermbangan karakter siswa yang memiliki tipe quitter, camper, dan climber.

Quitter yaitu keadaan seseorang yang mudah menyerah, camper yaitu suatu keadaan sehingga tidak ada keinginan dalam menghadapi tantangan dan climber yaitu tidak melanjutkan pendakian karena kurangnya tantangan.

\section{KESIMPULAN}

Dari hasil analisis, dapat disimpulkan bahwa learning cycle 7E dapat meningkatkan kemampuan pemecahan masalah matematis di sekolah menengah. Diperlukan juga keseriusan siswa pada saat proses pembelajaran agar siswa dapat menyelesaikan tugsnya dengan baik. Jika siswa tidak dapat menyelesaikan tugasnya dengan baik berarti siswa tersebut cenderung tidak siap belajar seperti malas, mengobrol, dan pasif dalam berdiskusi dengan kelompoknya. Sintaks pada learning cycle 7e berkaitan dengan indikator kemampuan pemecahan masalah matematis. Pada fase elicit yaitu mendatangkan pengetahuan awal siswa berkaitan dengan indikator pemecahan masalah matematis memahami masalah. Kegiatan yang dilakukan yaitu guru memberi pertanyaan pada siswa lalu siswa akan berusaha memahami apa yang ditanyakan oleh guru dan menjawab pertanyaan yang diberikan. Ketika guru bertanya sudah termasuk langkah agar pengetahuan siswa terbentuk yang kemudian membuatnya dapat memahami masalah tersebut kemudian peserta. Pada fase engage yaitu siswa dapat belajar berhipotesis yang berkaitan dengan indikator merencanakan masalah. Lalu pada fase explore atau menyelidiki, explain atau menjelaskan dan elaborate atau menerapkan berkaitan dengan indikator melaksanakan rencana penyelesain. Ketiga tahap diatas didalamnya berisi kegiatan kelompok dan terdapat diskusi untuk menyelesaikan masalah juga dapat membuat siswa menerapkan masalah 
tersebut dalam kehidupansehari-hari. Terakhir adalah fase evaluate dan extend berkaitan dengan indikator memeriksa kembali. Saat kegiatan evaluasi dan refleksi dilakukan penilaian dan terdapat penjelasan dari kesimpulan agar tidak terjadi perbedaan pemikiran, sehingga berkaitan dengan indikator memeriksa kembali.

\section{REFERENSI}

Akbar, P., Hamid, A., Bernard, M., \& Sugandi, A. I. (2018, Mei). Analisis Kemampuan Pemecahan Masalah Dan Disposisi Matematik Siswa Kelas XISMA Putra Juang Dalam Materi Peluang. Journal Cendekia : Jurnal Pendidikan Matematika, 2(1), 144-153.

Amelia, Sindi (2012). Pengaruh Accelerated Learning Cycle Terhadap Kemampuan Pemecahan Masalah Dan Koneksi Matematis Siswa Sekolah Menengah Pertama (Studi Kuasi-Eksperimen Pada Salah Satu SMP NegeriDi Pekanbaru). Tesis Jurusan Pendidikan Matematika UPI Bandung.

Anshori, M. I., Syaiful, \& Sofyan, H. (2020). Pengaruh Learning Cycle 7E disertaiMind Mapping Terhadap Kemampuan Pemecahan Masalah Matematika ditinjau dari Adversity Quotient. Jurnal Pendidikan Matematika, 11(2), 226-241.

Atieka, T. A., \& Budiana, I. (2019, Agustus). Pengaruh Model Eliciting Activities(Mea’s) Terhadap Kemampuan Pemecahan Masalah Matematis Dan Self Confidence Siswa. JPM : Jurnal Pendidikan Matematika, 5(2), 95-104.

Fadillah, S. (2009). Kemampuan Pemecahan Masalah Matematis Dalam Pembelajaran Matematika. Prosiding Seminar Nasional Penelitian, Pendidikan dan Penerapan MIPA (pp. 553-558). Yogyakarta: Fakultas MIPA, Universitas Negeri Yogyakarta.

Fauziah, R., Maya, R., \& Fitrianna, A. Y. (2018, September). Hubungan Self Confidence Terhadap Kemampuan Pemecahan Masalah Matematis Siswa SMP. JPMI: Jurnal Pembelajaran Matematika Inovatif, 1(5), 881-886.

Kurniawan, R., Putri, R. I., \& Sunaryati. (2020, Juli). Pemecahan Masalah Matematis Siswa Kelas VIII Menggunakan PMRI melalui LSLC pada Materi Gradien. Jurnal Elemen, 6(2), 346-356.

Nufus, H., Wira, C., \& Kurniati, A. (2019, September). Pengaruh Penerapan Model Learning Cycle 7E Terhadap Kemampuan Pemecahan Masalah Matematis Ditinjau Berdasarkan Kemandirian Belajar Siswa SMPN 31 Pekanbaru. Juring (Journal for Research in Mathematics Learning, 2(3), 199-210.

Putra, H. D., Putri, W. A., Fitriana, U., \& Andayani, F. (2018, July ). Kemampuan Pemecahan Masalah Matematis dan Self-Confidence Siswa SMP. SJME (Supremum Journal of Mathematic Education, 2(2), 60-70.

Ramdan, Z. M., Veralita, L., Rohaeti, E. E., \& Purwasih, R. (2018). Analisis Self Confidence Terhadap Kemampuan Pemecahan Masalah Matematis SiswaSmk Pada Materi Barisan Dan Deret. Aksioma, 7(2), 171-179.

Rumapea, R. (2018). Pengaruh Model Pembelajaran Kooperatif Tipe STAD dan Pemberian Soal Open-Ended Terhadap Kemampuan Pemecahan Masalah Matematis Siswa Ditinjau dari Kemampuan Awal Matematika. Journal Pendidikan Matematika, 12(1), 1-14.

Ruseffendi, E.T. (2006). Dasar-dasar Penelitian Pendidikan dan Bidang Non Eksakta Lainnya. Bandung: Tarsito

Ruseffendi, ET. (1980). Pengajaran Matematika Modern, Bandung: Tarsito.

Sari, D. P., Putra, R. W., \& Syazali, M. (2018). Pengaruh Metode Kuis InteraktifTerhadap 
Kemampuan Pemecahan Masalah Matematis Mata Kuliah Trigonometri. Jurnal Pendidikan Matematika, 12(2), 63-72.

Sumartini, T. S. (2016). Peningkatan Kemampuan Pemecahan Masalah MatematisSiswa Melalui Pembelajaran Berbasis Masalah. Mosharafa : Jurnal Pendidikan Matematika, 148-152.

TIMSS. (2012). TIMSS 2011 International Results in Mathematics. Chestnut Hill:TIMSS \& PIRLS International Study Center.

Wulandari, \& Sinambela, N. (2017, Agustus). Hubungan Kepercayaan Diri (SelfConfidence) Dengan Kemampuan Pemecahan Masalah Matematika Siswa Dengan Menggunakan Model Problem Based Learning di MAN Kisaran. Jurnal Inspiratif, $3(2)$. 